Original article

\title{
Valuation approaches to ecosystem goods and services for the National Botanical
}

\author{
Garden, Bangladesh
}

\author{
Jasia Tahzeeda*, Mizan R. Khan, Raisa Bashar
}

Department of Environmental Science and Management, North South University, Dhaka, Bangladesh E-mail address ( ${ }^{*}$ corresponding author): trishasia@gmail.com

\begin{abstract}
The main attractions of national parks include their scenic beauty, security, wildlife and trees. For preserving and maintaining national parks, an appropriate pricing policy can be used. The current study focuses on using the travel cost method (TCM) and contingent valuation method (CVM) as a non-market valuation technique to value the National Botanical Garden in Bangladesh, a developing country where little or no previous works of this kind has been conducted before. The main objective of the paper was to suggest an appropriate entrance fee for the park by assessing the willingness to pay (WTP) from the TCM and CVM; by determining a revenue maximizing entrance fee from the CVM; and by considering socio-demographics, the characteristics of visits and the motivation of the visitors to preserve the National Botanical Garden. The study sampled 100 visitors. These visitors participated in a survey which consisted of closed questions followed by a semi structured in-depth interview. For data processing, SPSS and Microsoft Excel were used. Based on the travel cost demand function using the TCM, the study found that the amount respondents were willing to pay for entrance was 0.955 US dollars and yearly consumer surplus was 593634.5 USD. From the CVM, it was estimated that the WTP was 0.225 USD for the entrance and revenue maximizing entrance fee was 0.376 USD. Finally, the entrance fee suggested for National Botanical Garden was around 0.225 USD.
\end{abstract}

KEY WORDS: consumer surplus, contingent valuation method (CVM), revenue maximizing entrance fee, travel cost method (TCM), willingness to pay (WTP)

ARTICLE HISTORY: received 6 November 2017; received in revised form 18 February 2018; accepted 13 March 2018

\section{Introduction}

Ecotourism can play a significant role in safeguarding natural resource conservation and economic growth. Ecotourism/nature tourism grew globally three times faster than the tourism industry as a whole in 2004 (ZAITON, 2008). Bangladesh has also introduced and revitalized its nature based tourism in its protected areas in cooperation with local people in order to conserve biodiversity. There are some parks in Bangladesh created for conserving biodiversity and ecotourism. But the park entry fees are often low and sometimes nonexistent and do not generate sufficient revenue for the management of parks in Bangladesh. Like any other environmental resources and public goods, the national Botanical Garden of Bangladesh is beneficial to society in many different ways.
It performs not only ecological functions but also provides recreational facilities to those who visit this area. Historically, the importance of botanical gardens was based on their status as centres for the study and understanding of plants, and on their usefulness to the developing science of medicine. Recently, however, these traditional uses of botanical gardens have diminished, and, with maintenance costs often exceeding revenues, their continued existence are under question (GARROD ET AL., 1993).

There are some methods to evaluate the ecosystem values and recreational services. Numerous non-market valuation studies have been widely conducted in the developed world, but very few non-market valuation studies have been carried out in the developing world (TIMAH, 2011). This may be due to a lack of research funding or insufficient data in these places. Additionally, it may 
be that researchers don't pay importance to the recreational places of developing countries due to the stigma that developing countries should only focus on the basic amenities related to development. Therefore they ignore the fact that developing countries can also earn revenue from recreational activities and can thus further their development. Improved facilities and infrastructure are likely to lead to both increased visitation and higher revenues in recreational places (GUHA \& GHOSH, 2009). On the other hand, unregulated tourism creates problems in for the preservation of wildlife in public parks especially in developing countries (BHARALI \& MAZUMDER, 2012). Thus in a developing country like Bangladesh, it is important to preserve ecologically critical areas and national parks in order to preserve biodiversity, regulate recreational activities and control unregulated tourism.

As in the developing countries the Government budget is substantially lower for protecting such areas, it is therefore vital to use a pricing method for determining entrance fees which will contribute towards revenue generation. Currently the entrance fee of the National Botanical Garden is 10 BDT (Bangladesh Taka) which is equivalent to 0.125 USD (United States Dollar) per head, which is underpriced. So, by increasing the entrance fee, more revenue can be generated. Thus, there is a clear need for implementing a proper entrance fee.

Policies to address environmental problems are increasingly relying on non-market valuations (KAREN ET AL, 2007). In this research non-market valuation techniques were used to determine an appropriate entrance fee. To do this both revenue maximizing entrance fee and willingness to pay were calculated. However, in this research travel cost method (TCM) and contingent valuation method (CVM) were used.

The research questions for the study were: 1 ) What is the willingness to pay from travel cost method and contingent valuation method? and 2) What is the revenue maximizing entrance fee from the travel cost method?

The specific objectives of this study were: 1) to identify the socio-demography of visitors, 2) to identify the characteristics of the visits made by visitors, 3) to identify the motivation of the visitors towards preserving the National Botanical Garden, 4) to calculate consumer surplus (CS) from a travel cost method's perspective, 5) to identify the willingness to pay (WTP) from TCM, 6) to calculate the revenue maximizing entrance fee from CVM and 7) to identify the WTP from CVM.

This study was carried out in 2016 at the National Botanical Garden of Bangladesh, located in Dhaka.

\section{Study area}

The National Botanical Garden of Bangladesh and the Bangladesh National Herbarium makeup the largest plant conservation centre in Bangladesh, with an area of around 84 ha (210 acres). It is located at Mirpur in Dhaka, beside the Dhaka Zoo. It was established in 1961. It is one of the greatest botanical gardens of Bangladesh, a knowledge centre for nature lovers and botanists and a tourist destination. The herbarium has a scientific collection of approximately 100,000 preserved plants specimens. It is divided into 57 sections, and it is managed by Forest Department under Ministry of Environment and Forests, Government of Bangladesh. Bangladesh National Herbarium's collection of plant and tree species is large. The garden houses about 56,000 individual trees, herbs, and shrubs including a huge collection of aquatic plants. The Government had an allocated budget for the development and non-development purpose of the National Botanical Garden of Bangladesh. For non-development, it received 556939.4875 USD; under the biodiversity project, it receives 73461.325 USD; and from Strengthening Regional Cooperation for Wildlife Protection Project (SRCWP) it received 5625 USD in 2016 (as per communication with Forest Department of Bangladesh).

\section{Materials and methods}

\subsection{Travel cost approach}

The travel cost method (TCM) is the longest established indirect revealed preference (RP) approach (BLAKEMORE \& WILLIAM, 2008). This method was initially introduced by CLAWSON (1959). TCM is relatively uncontroversial, because it is modelled on standard economic techniques for measuring value, and it uses information on actual behavior rather than verbal responses to hypothetical scenarios (LIMAEI ET AL., 2014). It is required to input values that reflect the true social costs and benefits of recreational activities using some techniques of environmental resources valuation. If the economic costs and benefits of outdoor recreation sites were not estimated using accepted environmental valuation techniques, conservation benefits could not be approximated (ENYEW, 2003). People's willingness to pay for the given site is expressed as cost per visitor day (HANLEY \& SPASH, 1993). This study is based on zonal approach of the travel cost method. TCM was used to capture the economic value of natural resources, as an integral part of designing economic incentives and a proper 
allocation for better management (ISLAM \& MAJUMdER, 2015). There is much research concerning the valuation of recreational sites (forest park, national park, beach etc.) using TCM such as: STEVENS \& ALLEN, 1980; DWYER ET AL., 1983; KNAPMAN \& STANLEY, 1991; CHEN ET AL., 2004; HERATH \& KenNEdY, 2004; Rolfe \& GREGG, 2012. However, there is little research regarding the valuation of recreational sites in Bangladesh (forest park, national park, beach etc.) using TCM such as: KAWSAR ET AL., (2015), SHAMMIN, (1999), ISLAM \& MAJUMDER (2015) etc. However research regarding the valuation of recreational sites in Bangladesh is scanty in number. The paper of ISLAM \& MAJUMDER (2015) provided a brief overview of economic valuation of natural resources including the travel cost method with a case study from Foy's Lake, Chittagong, Bangladesh. SHAmmin's (1999) paper used the TCM to determine willingness to pay for the services of the Dhaka Zoological Garden. The work of KAWSER ET AL. (2015) had targeted Lawachara National Park for quantifying the recreational value and the functional relationship between the travel cost and visiting a national park.

\subsection{The concept of consumer surplus (CS)}

TCM is based on calculating the Marshallian consumer surplus (BATEMAN, 1995). Consumer surplus (CS) is the difference between the total travel costs or expenses incurred by a visitor to a recreational site and the maximum amount he or she was (or would be) willing to spend in order to make the visit or trip (TiмAH, 2011). The consumer surplus is brought out, based on an assumption that the benefits gained from the same public goods or services are equivalent for every visitor. The further they travel, the more they pay. When travel costs exceed the benefit, the travel behavior won't happen (TANG, 2009).

\section{Revenue maximizing entry fee:}

Revenue is a function of price and quantity and equilibrium price is also a function of quantity which is described in Equation (1),

whereas,

$$
\mathrm{R}=\mathrm{PQ}=\mathrm{bQ}-\mathrm{mQ}^{2}
$$

$\mathrm{R}=$ revenue, $\mathrm{P}=$ price, $\mathrm{Q}=$ Quantity, $\mathrm{b}$ is the $\mathrm{y}$ intercept (intercept of the price), $\mathrm{m}$ is the slope.

To maximize the revenue, the derivative of the function must be zero. Thus, Equation (2) is:

$$
\mathrm{R}^{`} \mathrm{q}=\mathrm{b}-2 \mathrm{mq}=0
$$

\subsection{Contingent valuation method (CVM) and willingness to pay (WTP)}

For a valuation of the non-market goods of the National Botanical Garden, the contingent valuation method was used to elicit consumer preference of goods and services which were not directly traded in the market. The CVM is used to directly value the use and the non-use value of a natural resource (JABARIN \& DAMHOUREYEH, 2006).

The CVM has been used to value a change in the management of scientific collections (MWEBAZE \& BENNETT, 2011). CVM measures with respect to public goods and services reflect primarily a willingness to pay for a moral satisfaction of making a contribution to the preservation of these goods or resources on which they depend (AJZEN \& DRIVER, 1992).

It is a standardized survey method for estimating maximum willingness to pay (WTP) or willingness to accept compensation (WTA) for use, existence and bequest values for resources (Loomis, 1996). One of the most important concepts in CVM is willingness to pay. WTP is the maximum amount consumers are prepared to pay for goods or services (ZAITON, 2008). On the other hand, WTP is therefore the marginal benefit of environmental quality or the marginal rate of substitution between income and environmental quality (GREENSTONE \& JACK, 2013).

\section{Non-use Value and Existence Value}

"The use value of goods is the value attached to the current, future, or potential use of the goods. The non-use value is attached to goods independent of its use. Existence value falls under non-use value. According to TURNER (1999) existence value is a special form of altruism. BISHOP \& WELSH (1992) linked existence value to altruism towards animals and feelings of environmental responsibility. HANLEY ET AL. (1993) defined existence value as the value of mere existence of a resource, given that the individual has no plans ever to use it" (WEIKARD, 2005).

For this part of the research the concept of existence value is used to determine the motive of the visitors for preserving the National Botanical Garden.

\subsection{Questionnaire design}

A questionnaire with a semi structured interview was designed to gain information on WTP in this study. The survey questionnaire was chosen because it encourages a high response rate and is suitable 
for complex questions. The questionnaire was divided into five sections: Socio-demographic characteristics, characteristics of the visit, why the place should be preserved, characteristics of paying and what values could be added to preserve the place.

The first section of the questionnaire gathered information on the demography of visitors such as nationality, age, education and income. In this section the geographical area of the visitors such as which district they came from was included. The second section was designed to obtain information on characteristics associated with the National Botanical Garden such as mode of transport, total cost of visiting the place, (visiting rate) number of visits per year and reasons for visiting. In the third section respondents were given multiple choice questions about motives for preserving the National Botanical Garden, which had four alternatives. The first motive suggested benefitting through personal experiences. The second implied that other people would have the opportunity to enjoy the resource. A third category suggested the existence value which indicated that, the resource has a right to exist (WEIKARD, 2005). The fourth group was given the choice to deny such motives for preservation. Those who had marked only the first alternative, were considered to be "pure users". Those who marked only the second alternatives were considered to be altruistic. Those who considered the third alternative were "altruistic identifying existence value". Those who considered both first and second alternatives were "pure users and altruists", those who considered both first, second and third alternatives were considered to be "pure users, altruists and altruists identifying existence value". Those who considered only second and third were "altruists and altruists identifying existence value". The fourth section was designed to identify the characteristics of paying and the mean value of WTP for entrance fees at the National Botanical Garden. This section asked respondents how much they were willing to pay for the entrance fee. The question was posed to discover the willingness of visitors to pay a higher fee through a bidding game.

\subsection{Data collection method}

TCM requires information about the visitors to a recreational site. This information was collected by conducting an on-site survey of visitors to the National Botanical Garden, followed by a semistructured interview. The survey questionnaire was chosen because it provided assistance to respondents and was suitable for complex questions.
A systematic random sampling method was applied where every third visitors who entered the park was chosen as a sample. This method was chosen for its simplicity and the results derived from this method were likely to be representative. A sample size of 100 was selected. Respondents over 15 years of age were selected randomly for the survey and interviews. Only respondents over 15 years of age were selected for the survey, as the questionnaire included quantitative information and required analytical ability of the respondent. At age 15, an adolescent starts his mid-teens and in Bangladesh most children complete their secondary school at this age. Thus only respondents over 15 were selected for survey assuming their maturity to answer the questions properly.

\subsection{Data analysis}

Geographic divisions were used by calculating the distance from the site. The second step was to undertake the field work and collect data from each zone through the mixture of surveys and semi structured interviews. Then the actual number of visitors was collected. A regression analysis was carried out on the zones with the actual number of visitors as dependent variables. Our assumption was that the number of visitors would be inversely related to the travel cost. Data related to gender, age group, monthly gross income, academic education, characteristics of the National Botanical Garden, reasons for visiting, transportation mode and preservation related answers were analyzed. SPSS and Microsoft Excel were used to analyse the data. Consumer surplus and aggregate consumer surplus were calculated for each zone.

\subsection{Assumptions to eliminate TCM biases}

The ravel cost method has some common biases which were accommodated in the calculation of travel costs for each individual. It was considered that the value of time is one-third of the regular wage. This one-third of the daily wage has been used based on TCM studies carried out elsewhere in the world and may not be correct (SHAMmin, 1999). In this paper, the opportunity cost of time wasn't taken into account for several reasons. First of all, most of the people are students and it is assumed that in their leisure time they are into nonmonetary works. There are only few places to visit in Dhaka and people visit the area during the afternoon or during the holidays at times when they are not working, However, as most of the people who came from faraway do multiple visits and some of them also came to visit Dhaka Zoo, 
only half of the total travel cost was taken into account. There is an inherent bias in the paper. The data was collected during the fasting month; this is the month when few visitors visit the place. In other months of the year, the average number of people visiting the place is around 3000 to 3500 people, whereas in the month of Ramadan, the average numbers of people are between 1500 and 2000. However, the bias has been reduced by using an average number of people visiting during the month of Ramadan instead of using the yearly visits in order to calculate the willingness to pay.

\section{Results and discussion}

\subsection{Descriptive statistics}

31 of the respondents were female and the rest were male. It can be assumed that there might be some obstacles for females to visit the park. The reasons might be cultural as well as economic. Additionally, as many people have stated that the place is unsafe, it might be assumed that women don't feel secure visiting the area. From field observations, it was found that most of the women were accompanied by male partners. It was assumed that most of the people $(90 \%)$ were between the ages of 15 to 35. So, the National Botanical Garden is a recreational place mainly for young people. Most of the people have an educational background to higher secondary school or honours $(60 \%)$. The majority $(63 \%)$ of the people are students. $60 \%$ of the sample earn lower than 62.5 USD per month (personal income), followed by 26 of them who earn between 62.5 and 250 US dollar per month. Most of the people indicated that its scenic beauty $(68 \%)$ is the main characteristic of the Botanical Garden. 58 of the sample maintained that they used a public bus and 30 of them used a rickshaw to get to the place. 36 of them stated that their main motivation for preserving the forest was to be able to use the recreational facilities and gathing personal experiences; 66 of them stated that the main motivation for preserving the forest was to conserve and preserve this National Park for future generations; 19 of them maintained that the main motivation for preserving the forest was that the resource has its own right to exist. From this data, it can be assumed that 36 of them are pure users, 66 of them are altruists and 19 of them are "altruists identifying existence value". Those who marked the first alternative, were considered to be "pure users", in this case 36 people have stated that. Those who have marked the second alternative were considered to be "altruists"; in this case 66 people marked it. Those who have considered the third alternative were "altruists identifying existence value". In this case 19 people were "altruists identifying existence value".

\subsection{Zonal model of the TCM analysis}

The zonal model of the TCM Analysis is described in Table 1, where observed number of visit, actual number of visits (Vr), visits per population (Vrp), travel cost, travel cost adjusting for multiple site visits were mentioned.

Table1. Zonal model of the TCM analysis

\begin{tabular}{|c|c|c|c|c|c|c|c|}
\hline Zone & $\begin{array}{c}\text { Distance from } \\
\text { the site (km) } \\
\text { (both way) }\end{array}$ & $\begin{array}{c}\text { Population } \\
(\mathrm{p})\end{array}$ & $\begin{array}{c}\text { Observed } \\
\text { number of visit }\end{array}$ & $\begin{array}{c}\text { Actual number } \\
\text { of visits (Vr) }\end{array}$ & $\begin{array}{c}\text { Vrp=Vr/p } \\
(/ .00001)\end{array}$ & $\begin{array}{c}\text { Travel cost } \\
\text { (USD) }\end{array}$ & $\begin{array}{c}\text { Adjusted Travel } \\
\text { cost (ATC) (USD) }\end{array}$ \\
\hline A & $0-50$ & 6434424 & 86 & 1462 & 22.72 & 2.45625 & 2.45625 \\
\hline D & $151-200$ & 2416018 & 2 & 34 & 1.41 & 10.0 & 5.0 \\
\hline E & $201-250$ & 2845324 & 3 & 51 & 1.78 & 12.2875 & 6.14375 \\
\hline F & $251-300$ & 2480764 & 3 & 51 & 2.10 & 17.5 & 8.75 \\
\hline G & $301-350$ & 6430032 & 5 & 85 & 1.32 & 12.5 & 6.25 \\
\hline H & $351-400$ & 1489250 & 1 & 17 & 1.142 & 16.0 & 8.0 \\
\hline
\end{tabular}

The actual number of visits was calculated by multiplying observed number of visit and 17 . The total number of visitors to the site over the five day period was 8512 (as per Botanical Garden communication). Therefore, the sample can be converted to real data by multiplying the observed number of visitors by a factor of $(8512 / 5) / 100=17$. Travel cost was calculated as the average travel cost from that zone. Adjusted travel cost (ATC) was determined by considering the multipurpose visit. Thus half of the travel cost was considered for determining ATC for distances above $50 \mathrm{~km}$. 
The output depicted is shown in Fig. 1 which shows the results of fitting a curve to describe the relationship between zonal adjusted travel cost and the number of visits per population (Vrp) through inverse regression analysis. Equation (1) explains the curve as: number of visits per population $=76.280 /$ travel cost -9.786 .

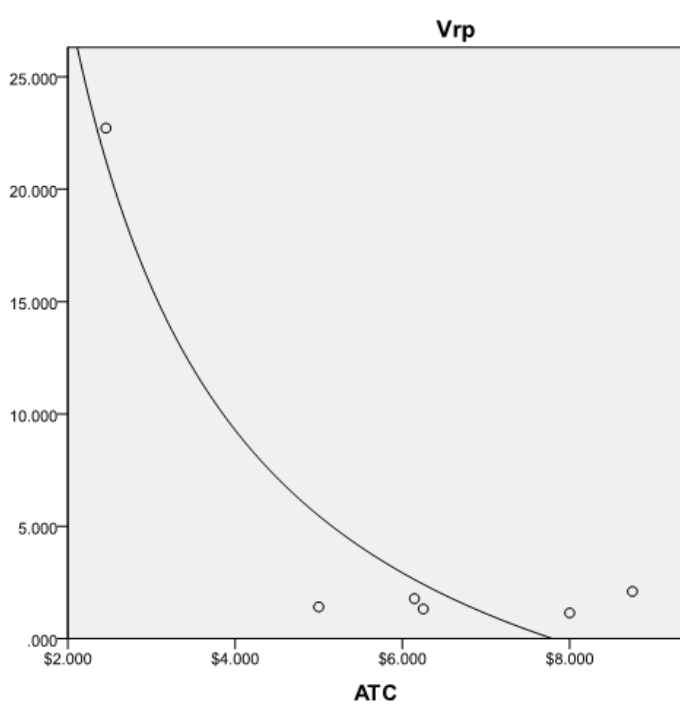

Fig. 1. Number of visits per population (Vrp) and adjusted travel cost (ATC)

\subsection{Total visit (TV) for each entry fee (EF)}

The first step was to calculate travel cost (TC) plus entry fee (EF) by summing the entry fee with travel costs from each zone. From Equation (2) and by multiplying visit/100,000 with the population and finally dividing that with 100,000 , total visits for each zone is calculated and then total visits for each entrance fee is calculated. Entrance fee and total visit are depicted in Table 2.

By using the linear regression the curve is estimated where EF is the independent variable and TV is the dependent variable, the result is depicted in Fig. 2.

Table 2. Entrance fee and total visit

\begin{tabular}{|c|c|}
\hline Entree fee (EF) (US Dollar) & Total visit (TV) \\
\hline 0.125 & 165408028 \\
\hline 0.1875 & 158721224 \\
\hline 0.250 & 152100528 \\
\hline 0.375 & 140021686 \\
\hline 0.625 & 118438403 \\
\hline
\end{tabular}

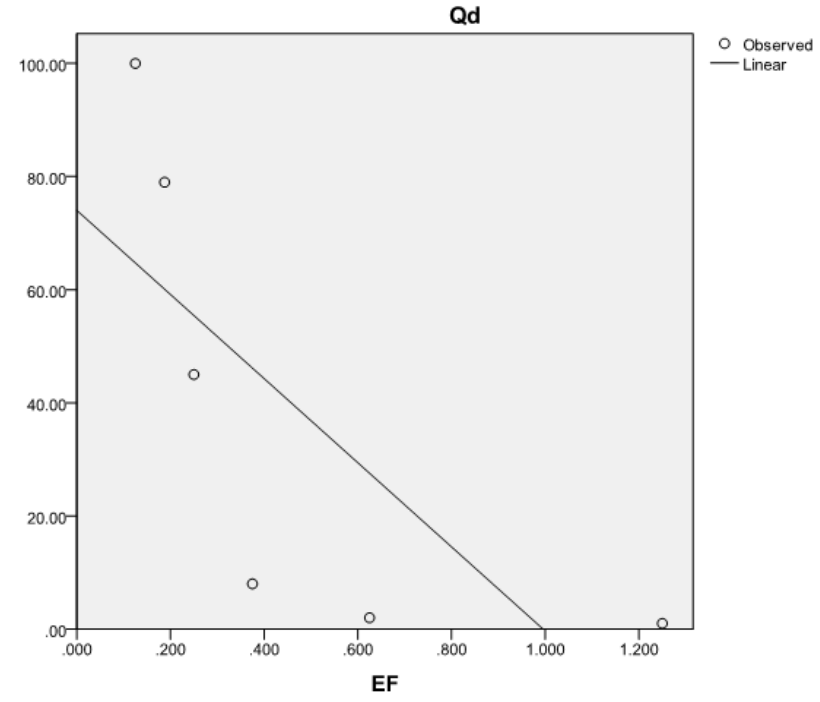

Fig. 2. Total visit (TV) and entree fee (EF)

Thus, Equation (3) is derived from the linear regression. Thus, total visits $=1761.231-(934.61$ $\mathrm{X}$ entrance fee).

\subsection{Consumer's surplus (CS) and total consumer surplus (TCS)}

Regression analysis was done on entrance fee and total visits. Finally consumer surplus for each was calculated by using the triangular formula. For calculating consumer surplus, first data was arranged based on each zone and then Equation (3) was derived by considering ATC and Vrp. Then this equation was used to calculate the demand for each proposed entrance fee. Then, for each entrance fee, total visit were rearranged based on each zone. Therefore, regression analysis was calculated on its entrance fee and total visit. Finally, consumer surplus will be calculated by using the triangular formula. Total consumer surplus is the summation of the consumer surplus from all these zones. Total consumer surplus is $=1626.4$ USD daily. Thus, yearly, it is around = 593634.51 USD.

\subsection{Willingness to pay (WTP) in travel cost method (TCM)}

The average daily total number of visitors during the period of time when the data was collected at the National Botanical Garden was 1702.4 (as per National Botanical Garden communication). Thus, yearly total number of visitors is $=(1702.4 \mathrm{X}$ $365)=621376$. 
In the travel cost method (TCM), willingness to pay $(\mathrm{WTP})=$ yearly consumer surplus/total number of visitors. Thus, WTP to pay (in USD) $=$ $593634.51 / 621376=0.95535$.

\subsection{Contingent valuation}

Entrance fee and quantity demanded (Qd) by using the contingent valuation method is depicted in the Table 3. In the next step, weighted average is used to figure out the willingness to pay. It was found that in contingent valuation method, willingness to pay (WTP) is 0.223 USD.

Table 3. Maximum Willingness to pay and Quantity demanded by using CVM

\begin{tabular}{|c|c|}
\hline Maximum WTP (USD) & Quantity demanded \\
\hline 0.125 & 21 \\
\hline 0.1875 & 34 \\
\hline 0.25 & 37 \\
\hline 0.375 & 6 \\
\hline 0.625 & 1 \\
\hline 1.25 & 1 \\
\hline
\end{tabular}

\subsection{Revenue maximizing fees}

Entrance fee and quantity demanded (Qd) by using contingent valuation method is depicted in the Table 4.

Table 4. Entrance fee and Quantity demanded by using contingent valuation method

\begin{tabular}{|c|c|}
\hline Entrance fee (USD) & Quantity demanded \\
\hline 0.125 & 100 \\
\hline 0.1875 & 79 \\
\hline 0.25 & 45 \\
\hline 0.375 & 8 \\
\hline 0.625 & 2 \\
\hline 1.25 & 1 \\
\hline
\end{tabular}

Thus Equation (3) is derived from Fig. 3, where $\mathrm{EF}$ indicates entrance fee and Qd indicates quantity demanded: $\mathrm{EF}=.752-.007 \mathrm{X}$ Qd. Revenue maximizing fees and quantity is derived from Equation (2) and Equation (3). Quantity is 53.714 and entrance fee is 0.376 USD.

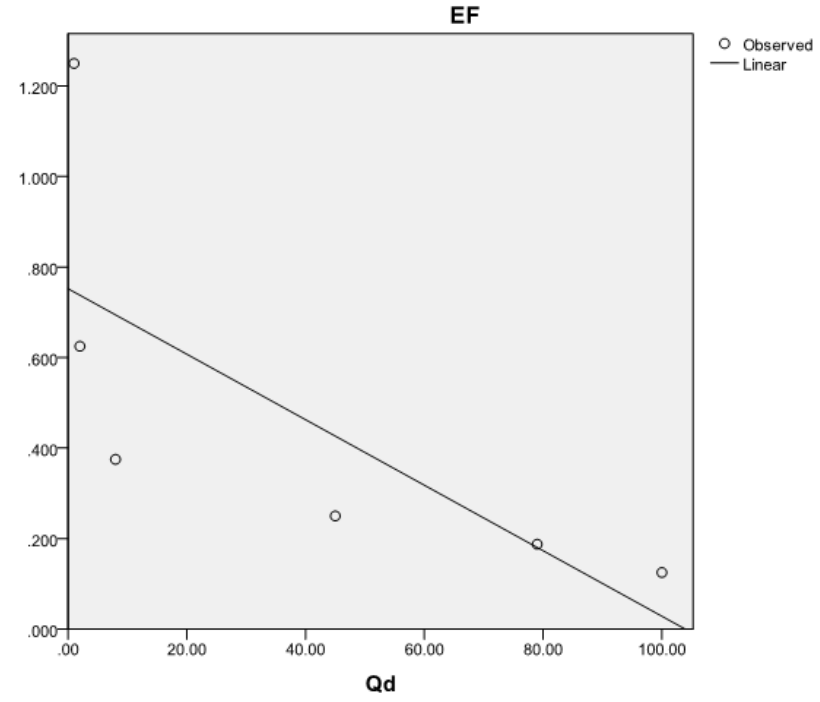

Fig. 3. Demand curve indicating quantity demanded (Qd) at different entrance fee (EF)

\subsection{Key findings}

- Average number of visitors per day during the time when the sample was collected was 1702.4

- Revenue from tickets per day during the time when the sample was collected was $=(1702.4$ $\mathrm{X} 0.125$ ) $=212.8$ USD

- Using TCM at current entry fee of 0.125 USD, consumer surplus was found to be 1626.40 USD daily

- Using TCM, yearly consumer surplus was found to be 593634.5 USD

- Willingness to pay from TCM is 0.9555 USD per head

- From contingent valuation, it was found that the willingness to pay is 0.223 USD. From contingent valuation, it was derived that the revenue maximizing entrance fee is 0.376 USD and quantity is 53.714 .

- Most of the people (63\%) are students and they belong to the 18-25age group. Among them 43 are between the age of 18 and 25, and 34 of them are aged between 26 and 35. Moreover, most of the people's (78\%) personal income range is below 65 USD per month.

- Most of the people who visit this place are from nearby places (86 out of 100). Furthermore, the majority of these people are from areas which are very near, such as Mirpur. Thus, it is not viable to increase the price too much without making significant quality improvements.

- $36 \%$ of the visitors are pure users, $66 \%$ are altruists and $19 \%$ are "altruists identifying existence value".

- However, from the unstructured interview, it was found that improved facilities and infrastructure are also likely to boost visitation 
and revenues. Moreover, many visitors complained about the degrading environment of the area, as many unscrupulous people come and harass others. They also maintained that the security is low at that place, thus many people can't explore properly and refrain from visiting this place.

- Some of them stated that there was a lack of entertainment facilities and sitting arrangements. However, few people stated that the price shouldn't be increased as many people visit the place only for walking purposes and they wouldn't be interested to pay a higher entry fee. Some also suggested that there should be a monthly or yearly scheme if the price was increased. There should be more research on this issue as well.

- As most of the people are below the age of 35; there should be more entertainment facilities for this age group in the area.

- It may be rationalized as there are very few places to visit in Dhaka for recreational activities and the high price can be justified by providing adequate amenities which might attract people to come and visit the area.

\subsection{Limitations}

However, there are some inherent biases in the paper. First of all, the sample size was small. Thus, while zoning the area for TCM, it was found that in Zone B and Zone $\mathrm{C}$, there was not even a single observed visit, so actual visits was zero from these areas. Another shortcoming was that the data was collected during the fasting month; this is the month when few visitors visit the place. In other months of the year, the average number of people visiting the place is around 3000 to 3500 people, whereas in the month of Ramadan (fasting), the average numbers of people are between 1500 and 2000. However, in order to reduce the bias the average number of people visiting during the month of Ramadan was used instead of using the yearly visitation for calculating willingness to pay.

\section{Conclusion}

The National Botanical Garden provides numerous benefits to the country both from an economic and an environmental perspective. This study produced interesting information about the value people attached to the National Botanical Garden, Bangladesh and provided an economic justification for government planners to place a higher priority on the maintenance and development of this site. In this research both the travel cost method (TCM) and contingent valuation method (CVM) were used to determine the value of nonmarket goods and services by determining the willingness to pay. Additionally, these methods were used to estimate the practicality and viability of increasing the entrance fee at the National Botanical Garden of Bangladesh.

From the reveled preference method TCM, it was established that the willingness to pay is 0.955 USD. From the stated preference method, CVM it was found that the willingness to pay for ticket price was 0.223 USD. Additionally, the revenue maximization entrance fee was 0.376 , which is significantly higher than the willingness to pay by CVM. Thus, it is highly important to increase the quality of the place which will attract more visitors and increase the willingness to pay.

The study also derived the socio-demographic, characteristics of visitors and the motives of visitors for preserving the National Botanical Garden. It was found that most of the visitors were students, with a personal income less than 65 USD per month. It was also found that the majority of the visitors were altruists who wanted others to enjoy the natural resources of the National Botanical Garden. Additionally, significant numbers of visitors fall under the category of "altruist identifying existence value", who ultimately care about the environment and feel a sense of responsibility towards it.

However, from the current study it can be suggested that the entrance fee should be increased moderately considering the occupation, age and income of the visitors. The entrance fee is suggested to be around 0.223 USD as predicted by willingness to pay from CVM. From the study it was estimated that increasing the entrance fee to 0.223 USD will be both appropriate and acceptable to the consumers. This would immediately generate additional revenue to cover the operating and maintenance expenses of the National Botanical Garden of Bangladesh.

\section{Acknowledgment}

The author would like to give thanks to Dr Faiyaz Al Zamal from McGill University in Canada and Mr Mahbub Zamal for their special support. Finally, special thanks to the National Botanical Garden for its co-operation and services.

\section{References}

Ajzen I., Driver B.L. 1992. Contingent Value Measurement. On the Nature and Meaning of Willingness to Pay. Journal of Consumer Psychology, 1, 4: 297-316. 
Bateman I.J., Langford I.H., Turner R.K, Willis K.G., Garrod, G.D. 1995. Elicitation and truncation effects in contingent valuation studies. Ecological Economics, 12: 161-179.

Bharali A., Mazumder R. 2012. Application of travel cost method to assess the pricing policy of public parks: The case of Kaziranga National Park. Journal of Regional Development and Planning, 1(1): 41-50.

Blakemore F., William A. 2008. British Tourists' Valuation of a Turkish Beach Using Contingent Valuation and Travel Cost Methods. Journal of Coastal Research, 24 (6): 1469-1480.

Chen W., Hong H., Liu Y., Zhang L., Hou X., Raymond M. 2004. Recreation demands and economic value: an application of travel cost method for Xiamen Island. China Economic Review, 15, 4: 398-406.

Clawson M. 1959. Methods of Measuring the Demand for a Value of Outdoor Recreation. Washington, DC, Resources for the Future: 36.

Dwyer J.F., Peterson G.L., Darragh A.J. 1983. Remove from marked records estimating the value of urban forests using the travel cost method. Journal of Arboriculture, 9: 182-185.

Enyew S. 2003. Valuation of the Benefits of Out-door Recreation Using the travel Cost method: the case of WabiShebelelangano Recreational Site. Adis Ababa University.

Garrod G., Pickering A., Willis K. 1993. The Economic Value of Botanic Gardens: a Recreational Perspective. Geoforum, 24 (2): 215-224.

Greenstone M., Jack B.K. 2013. Envirodevonomics: A Research Agenda for a Young Field. NBER working paper (19426).

Hanley N., Spash C. 1993. Cost benefit Analysis and the Environment. London: Edward Elgar Publishing Ltd.

Herath G., Kennedy J. 2004. Estimating the economic value of Mount Buffalo national park with the travel cost and contingent valuation models. Tourism Economics, 10: 63-78.

Indrila G.I., Ghosh S. 2009. Glimpse of the Tiger: How much are Indians willing to pay for it? (Working Paper No. 39-09). Retrieved from SANDEE economics and environment http://www.sandeeonline.org/uploads/documents/publ ication/846_PUB_Working_Paper_39.

Islam K., Majumder S.C. 2015. Economic Evaluation of Foy's lake, Chittagong using travel cost method. Indian Journal of Economics and Development, 3(8): 1-6.

Jabarin A.S., Damhoureyeh S.A. 2006. Estimating the Recreational Benefits of Dibeen National Park in Jordan Using Contingent Valuation and Travel Cost Methods. Pakistan Journal of Biological Sciences, 9 (12): 2198-2206.

Karen M., Sue S., Richard S.J. T. 2007. Comparing the Travel Cost Method and the Contingent Valuation Method - An Application of Convergent Validity Theory to the Recreational Value of Irish Forests. The Economic and Social Research Institute (ESRI), Dublin, No. 190.
Kawsar M.H., Pavel A.A., Uddin M.B., Rahman S.A., Mamun M.A.A., Hassan S.B., Alam M.S., Tamrakar R., Wadud M.A. 2015. Quantifying Recreational Value and the Functional Relationship between Travel Cost and Visiting National Park. International Journal of Environmental Planning and Management, 1 (3): 84-89.

Knapman B., Stanley 0. 1991. A Travel Cost Analysis of Recreation Use Value of Kadau National Park. Canberra, Resource Assessment Commission Inquiry: 42.

Limaei S.M., Ghesmati H., Rashidi R., Yamini N. 2014. Economic Evaluation of natural forest park using the travel cost method. Journal of Forest Science, 60(6): 254-261.

Loomis B.J., Yorizane S., Larson D. 2000. Testing significance of multi-destination and multi-purpose trip effects in a travel cost method demand model for whale watching trips. Agricultural Resource Economics Review, 29: 183-191.

Mwebaze P., Bennett J. 2011. Valuing Botanic Collections: A Combined Travel Cost Collections: A Combined Travel-Cost and Contingent Valuation Survey in Australia. https:// ageconsearch.umn.edu/bitstream/100688/2/Mwebaze.pdf

Rolfe J., Gregg D. 2012. Valuing beach recreation across a regional area: The Great Barrier Reef in Australia. Ocean \& Coastal Management, 69: 282-290.

Shammin R.M. 1999. Application of the travel cost method (TCM): A case Study of Environmental valuation of Dhaka Zoological Garden. IUCN, Switzerland.

Stevens T.H., Allen P.G. 1980. Estimating the benefits of recreation under conditions of congestion congestion. Journal of Environmental Economics and Management, 7: 395-400.

Tang T. 2009. An Application of Travel Cost Method to Yuelu Mountain Park in Changsha, China. (Master's Thesis, University of Helsinki).

Timah P.N. 2011. Non-market Valuation of Beach Recreation using the Travel Cost Method (TCM) in the Context of the Developing World: An Application to Visitors of the Ngoé Beach in Kribi, Cameroon. (Master's Thesis, Swedish University of Agricultural science).

Weikard H.P. 2005. Why non-use values should not be used. Mansholt Graduate School working paper (22).

Zaiton S. 2008. Willingness to pay in Taman Negara: A contingent Valuation Method. International Journal of Economics and Management, 2 (1): 81-94. 